.

\title{
USE EFFECTS ON THE REFLECTION OF MACRO TEXTURED SURFACES
}

\author{
Ixtaina P. A ${ }^{\mathrm{a},}$, Armas A. ${ }^{\mathrm{a}}$, Bannert B. ${ }^{\mathrm{a}}$, Marin G.H. ${ }^{\mathrm{a}}$ \\ ${ }^{a}$ Laboratorio de Acústica y Luminotecnia de la Comisión de Investigaciones Científicas de la Provincia de Buenos Aires LAL CIC, \\ Camino Centenario e/505 y 508 (1897) Gonnet - Argentina, http://www.cic.gba.gov.ar/ \\ *Comisión de Investigaciones Científicas de la Provincia de Buenos Aires LAL CIC, Calle 10 y 526 La Plata - Argentina
}

Received: 10.03.2016 / Accepted: 15.04.2016 / Revised: 20.05.2016 / Available online: 31.05.2016

DOI: 10.1515/jaes-2016-0007

KEY WORDS: led, lighting, road, surfaces

\begin{abstract}
:
The emergence of led luminaries in street lighting has modified traditional design guidelines. The highest led energy efficiency allows keeping suitable lighting levels with less installed power. Thus, the present design line of a street lighting installation is closely related to the technological change: kind of led to be used, suitable lens, efficacy relationship regarding high pressure sodium, light colour temperature, spectrum. The "impact" associated to with led conversion relegates main aspects of street designs: effect of road reflective properties and installation depreciation. The wear produced by traffic, as well as the environmental conditions gradually modifies the road reflection matrix. In a street lighting installation, this change alters the luminance arrangement on the road together with the perception conditions. This phenomenon is a determining factor within the global concept of depreciation affecting lighting systems in general and also street lighting installations designed by the Luminance Technique. In the present work changes, due to use, in the shape of street reflection matrices of Argentinean highways are analyzed. The analyzed r-tables were obtained through "in-situ" measurements, with road reflectometer. A first group corresponds to the initial conditions of macro textured roads which were measured in the period 2001/2003. The second studied set contains r-tables of the same type, and according to its use the surfaces can be considered in steady state, assessed between 2005 and 2009. The study provides information about the shape of matrixes and its alteration, specularity and scale factor, relating such parameters with the possible effects on the resulting lighting.
\end{abstract}

\section{INTRODUCTION}

As to street lighting, the driver's visual perception is conditioned by luminance arrangement on the road of the illuminated route. In this model of vision phenomenon, known as Luminance Technique, the reflection properties of the road surface are characterized by the luminance coefficient “q". In the standardized configuration for vision in routes (CIE, 1982; De Boer, 1967), shown in Figure 1, the punctual luminance L on the road, from the observer's point of view (driver), is determined, for each position, by the relationship between this coefficient, the intensities emitted by the luminary $-\mathrm{I}(\mathrm{C}, \gamma)$ - and the assembly height -h-.

$$
L=q(\beta, \gamma) \frac{I(C, \gamma}{h^{2}} \cos ^{2}(\gamma)
$$

The luminance coefficient depends obviously on the nature of the road surface material (its texture, colour, composition), on the observer's positions and on the luminous source with respect to the considered point. The coefficient, at first, results in a function of four variables:

$$
q=F(\alpha, \beta, \gamma, \delta)
$$

However, for the observation conditions corresponding to car drivers in routes, the angles $\alpha$ and $\delta$ do not present great variations, therefore fixed values have been adopted for both $\left(\alpha=1^{\circ}\right.$ and $\delta=0^{\circ}$ ), thus q can be considered only dependent on $\beta$ and $\gamma$.

\footnotetext{
*Corresponding author, e-mail: pixtaina@yahoo.com
} 
GE

DEG GQUTTER

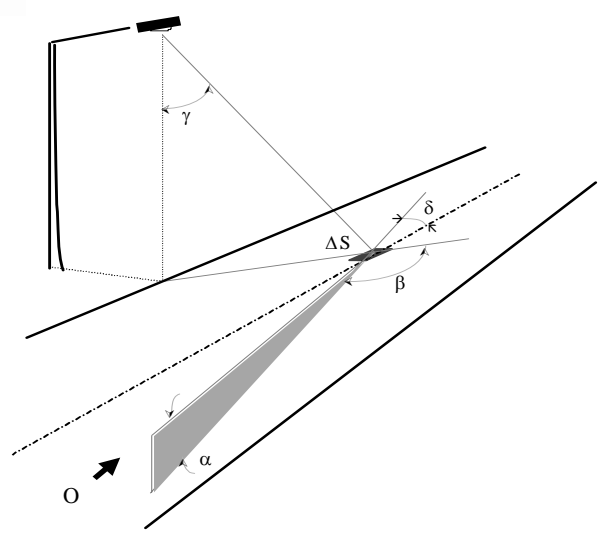

Figure 1.Vision in routes

Due to simplicity in calculation (for the limitations existing during the 1970s and 1980s, when the Technique appeared) it was more convenient to work with the so-called "reduced luminance coefficient”, " $\mathrm{r}(\beta, \tan \gamma)$ ”, defined as:

$$
r\left(\left(, \tan ()=q(\beta, \gamma) \cos ^{3}(\gamma)\right.\right.
$$

Thus, in order to know the reflective characteristics of a road, "r" values must be obtained for the observation and illumination conditions given in routes. The set of " $\mathrm{r}$ " values is expressed in a matrix (reflection matrix or r-table) with a standardized format, for a combination of $20 \beta$ values and $31 \gamma$ angles.

If $\mathrm{E}$ is the punctual luminance on the road [lx], the equation (1) can be written as:

$$
\mathrm{L}=\mathrm{q}(\beta, \gamma) \mathrm{E}
$$

The luminance coefficient can be considered then as a proportionality factor, for each point of the road, between illuminance and luminance. In this sense, the average luminance coefficient Qo that quantifies the degree of "lightness" of the road surface is defined:

$$
Q_{0}=\frac{1}{\Omega_{0}} \int_{\Omega_{0}} q d \Omega
$$

In equation 5 , $\Omega$ represents the solid angle underlying the element $\Delta$ s of Figure 1.

Higher values of Qo, associated to with "lighter" roads, will allow obtaining an increase of in average luminance, for the same illumination system (equal to E). In other words, Qo has a direct link with energy saving, in all similar to the highest efficacy of the luminous source. We save energy both if we obtain a more efficient led source and if we achieve a lighter road.

Based on standard roads of the CIE R series (CIE, 1982), the value for Qo ranges from 0.08 to $0.10 \mathrm{~cd} / \mathrm{m} 2 \mathrm{~lx}$.

However, studies carried out in Argentinean highways (Ixtaina, 2013) found greater differences. The studied roads, of "drainage" type, installed in the "Access System" to the metropolitan zone of this country had coefficients in the range of 0.06 to $0.11 \mathrm{~cd} / \mathrm{m} 2 \mathrm{~lx}$. The study (Ixtaina, 2013) showed that the right road choice (one "light"illuminated and another one "dark") can result in energy saving, up to more than $40 \%$. It is worth noting that the led luminary efficiency (at present in the order of $130 \mathrm{~lm} / \mathrm{W}$ ) compared to the traditional luminaries ( $\approx 96$ $\mathrm{lm} / \mathrm{W}$ combining lamp and LOR luminary performance) allow obtaining similar energy savings.

\section{CHANGES IN THE REFLECTION MATRIX}

A possible model to qualitatively explain the reflection phenomenon on the roads assigns two kinds of texture to the surface: one coarse, perceptible to the touch or sight (macro texture) and another one thin, imperceptible, the micro texture (De Boer, 1980). The micro texture would be responsible for a reflection of regular or diffuse type; the interaction with the coarse roughness would produce special reflection directions, associated with higher or lower specularity levels. Figure 2 shows the road surface according to this concept.

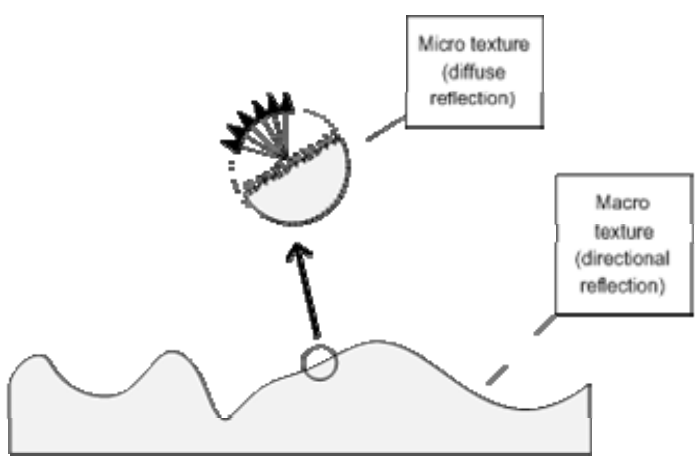

Figure 2. Road surface texture

This explanatory model is useful just to describe the phenomenon, since it could not be quantified. However, from this model it can be inferred that the traffic, when smoothing out the surface, would diminish the macro roughness. Thus, the use would change the relationship between micro and macro textures, favouring the prevalence of the former. The road, then, would evolve from its more specular original state, to another steady and more diffuse. So, it would be expected that the luminance uniformities (general, Uo and longitudinal, Ul) increase and that the lightning improves during the first months of use. It can also be added that the circulation would leave dark sediments, which together with the dirt effects, would reduce the light reflected by the road. This effect, along with the natural decrease of the illuminated flow in lamps, would fall to the average luminance value over time.

The studies to verify the theory previously described have been scarce and go back to the end of the 1980s. In their work about road characterization, Bodmann and Schmit (Bodmann $\mathrm{H}$, Schmidt H, 1989) studied the evolution of roads with more than a dozen of installations in a region from Germany. The research took almost two years and even though the obtained data were not conclusive, it was observed a significant decrease 


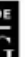

of the specular factor S1 during the first months of use, followed by a final stabilization (Figure 3).

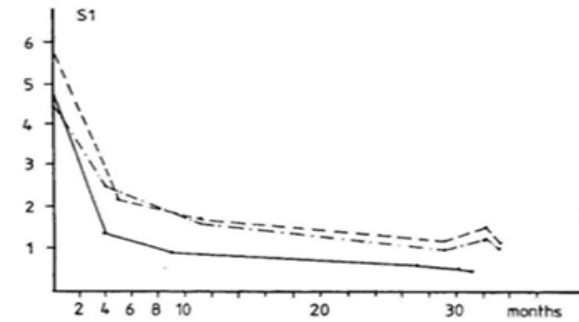

Figure 3. S1 evolution (from Bodmann \& Schmidt, 1989)

The evaluations of the installations carried out in the same work were coherent with this decrease in road specularity, showing an improvement of uniformities in luminance (Figure 4).
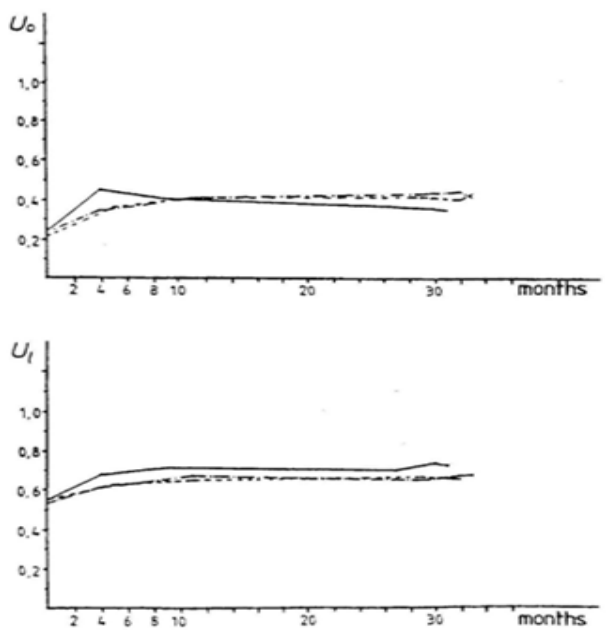

Figure 4. Evolution of uniformities (from Bodmann \& Schmidt, 1989)

Besides, Bodmann's studies detected a fall in the average luminance coefficient during the first months of use, which can be directly associated with a global decrease in the light reflected by the road. In line with this fact, the diminution of the average value of luminance was observed (Figure 5).
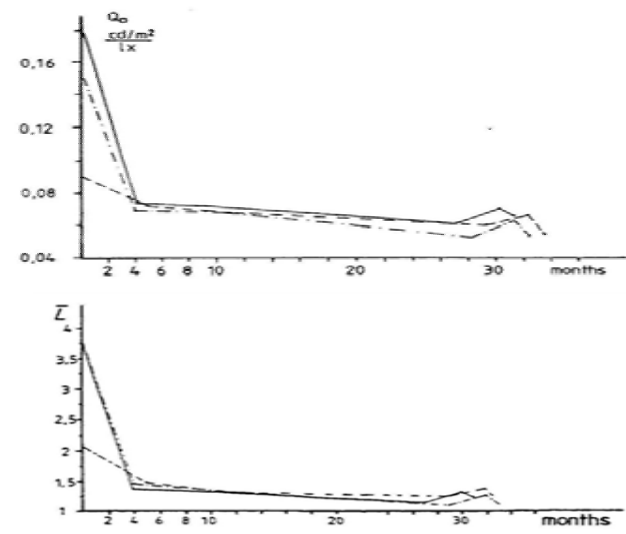

Figure 5. Evolution of the average luminance coefficient and the average luminance of the installation (from Bodmann \& Schmidt, 1989)

Finally, the analyzed surfaces became steady within a maximum period no longer than of six months.
These results were in agreement with the previous works, which even though they spanned a longer period of time, they involved a not very significant number of samples (Ziegler, 1980; FHWA 1986).

\section{LOCAL STUDIES}

The results previously shown can hardly be applied to roads of our region (metropolitan area, Argentina). On the one hand, the studies date back nearly forty years, undoubtedly a period that implies changes in technology for the formulation of asphalt compounds, materials and application techniques. On the other hand, there are local features: it is highly unlikely that the base materials used in a European region in the 1980s could be similar to those used in our zone. In addition to this, the roads of the local highways are mostly of "macro textured" type (draining), surfaces which have been mainly used in the last fifteen years.

The trend of the European research has not been verified by the local studies (Ixtaina, 2005). This study was based on the sixmonth evaluation, for three years, of the characteristic parameters of luminance (average luminance, general and longitudinal uniformities) and of illuminance, from the opening of the route (new road). Even though the results showed a gradual decrease in the average luminance values (Figure 6), the average fall was significantly slighter than in the European case. The general uniformity Uo did not present great changes while there was a significant fall of the longitudinal uniformity with use, which can be attributed to an increase in road specularity (Figure 7).

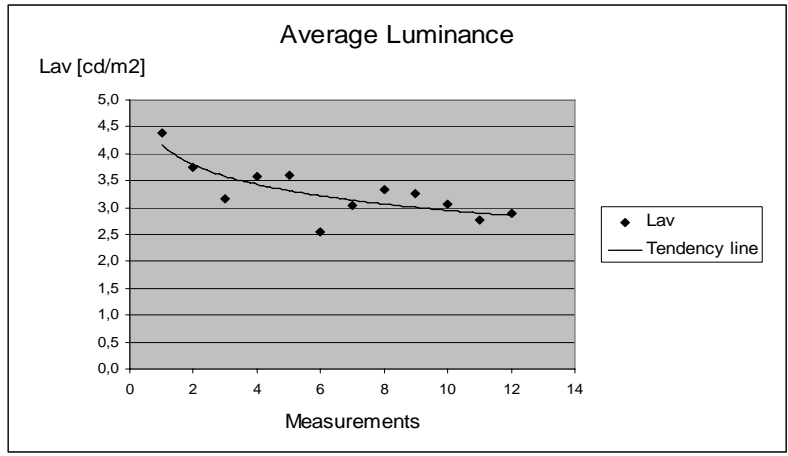

Figure 6. Evolution of the average luminance (Ixtaina, 2005)

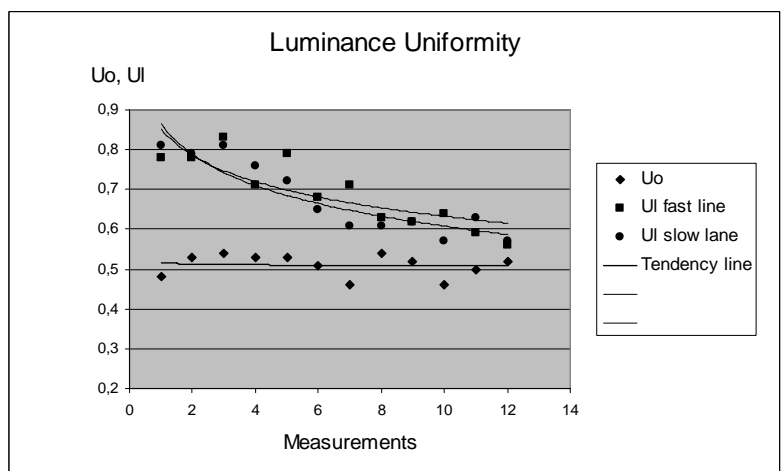

Figure 7. Evolution of uniformities (Ixtaina, 2005) 
$\overline{\mathrm{G}}$<smiles>[Li][14CH3]</smiles>

\section{ROAD MEASUREMENT}

In the present work, and as a complement of the previous study, a direct assessment of reflection matrices was carried out. All the analyzed r-tables were obtained by means of "in-situ" measurements, with road reflectometer (Ixtaina, 2005; Vidal, 2002; Ixtaina, 2008). The equipment used is of local design, non compact. It consists of a detector (luminance meter) that focuses the area to be evaluated in a low-flying way (Figure 8), according to the vision standardized conditions in route.

The illumination system is at $2.5 \mathrm{~m}$ from the detector. It consists of a detachable metallic arc which is installed on the measuring area and supports a projector. This has a set of diaphragms which enables covering a surface of around 0.50 by 0.25 , similar to the size of a standard test specimen, as that required by CIE 30.2.
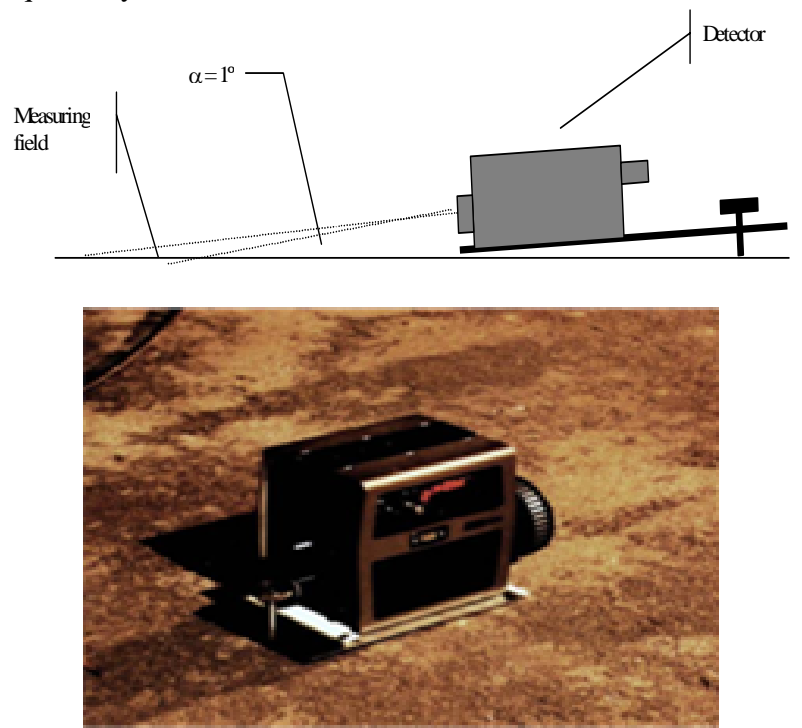

Figure 8. Assembly of the detector in the reflectometer LAL CIC

In turn, the luminous source can be displaced over the arc to adjust the angular values $\gamma$ established by the description parameters of the System LAL CIC (Figure 9).

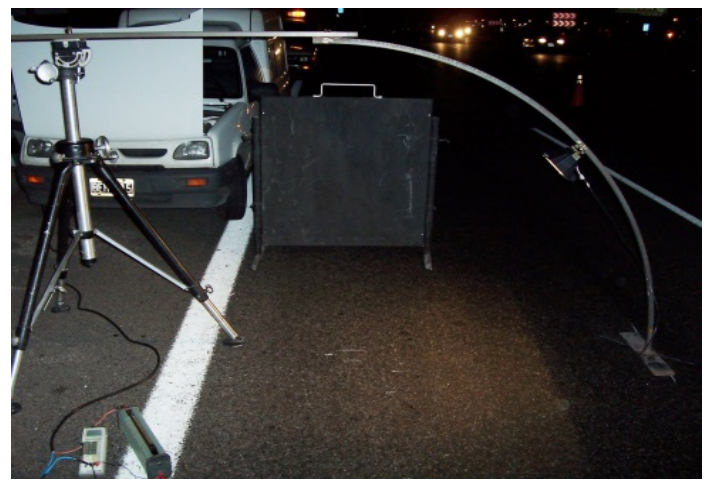

Figure 9. Luminous source assembly

\section{ASSESSED ROADS}

The first group corresponds to the initial conditions of the macro textured roads which were measured in the period 2001/2003. The obtained tables, called HSI type, correspond to the first local applications of the new draining compounds.

Their state can be considered as "initial", since they had been used between four months and a year (West and North Access to Buenos Aires City). Besides, a case as new is included, practically without circulation.

The outstanding feature of these r-tables is their high specularity, which which make them not assimilable to traditional roads, generally classified as R3 or R4 according to CIE.

The second group, surfaces called HSE type, has r-tables assessed between 2005 and 2009, also of the macro textured type with between three and eight years of use with three to eight years of use, which allows inferring that they would be in a state considered as steady.

\section{RESULTS}

\subsection{New surfaces}

Six areas in four highways of the Access System to Buenos Aires were studied by almost twenty applications of reflectometer from 2001 to 2003.

All the roads were of the macro textured type. The obtained rtables could be grouped in two characteristic shapes. On the one hand, HSI-1, of a very high specularity, was in agreement with surfaces with less circulation among the studied ones. Its features are indicated in Figure 10.

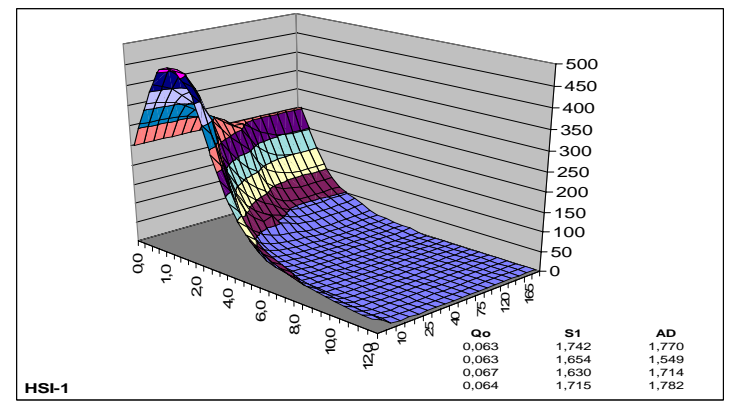

Figure 10.Table 1, representative of roads with little circulation

The second set, HSI-2, slightly smoother, corresponds to roads with almost a year of use (Figure 11). 
GE DE GRUYTER

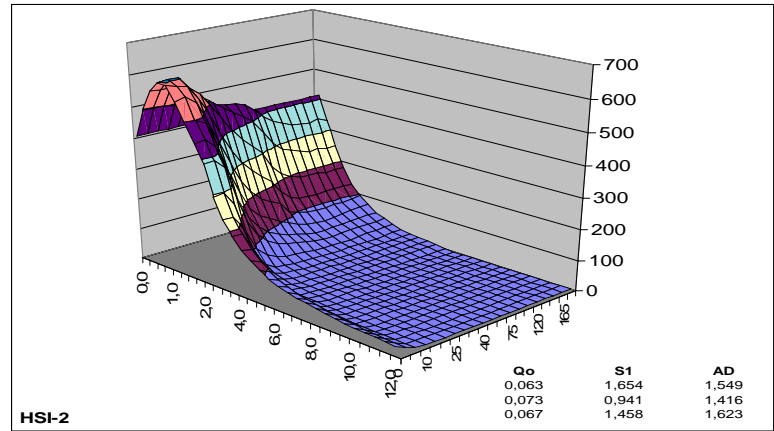

Figure 11.Table 2, representative of roads with little circulation

Comparing both groups it is noteworthy that: on the one hand, both have very similar values in their average luminance coefficients Qo. Despite this, the roads corresponding to table HSI-1 seemed significantly darker, even wet. On the other hand, HSI-1 has a more noticeable reflection "peak" than HSI2, however, both are of high specularity, according to S1 and $\mathrm{AD}$ values close to $1.5-1.6$.

\subsection{Surfaces with high traffic load}

About a dozen of areas were assessed by means of around 30 reflectometer applications from 2005 to 2009. The surfaces, all with macro textured roads, had been used between two years and a half (Buenos Aires City urban highways) and seven years (La Plata Buenos Aires city interconnection highway) without recoating or modifications in the analyzed zones (Vidal, 2003).

An important coincidence between measurements was observed, and this allowed obtaining a single r-table apt for representing them (Figure 12).

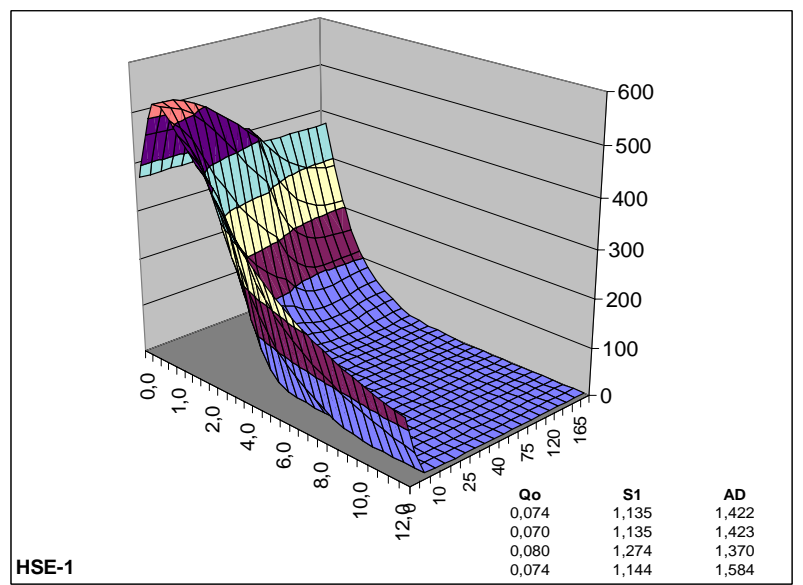

Figure 12. Representative table of roads in steady state

As characteristic points, a slight increase in Qo with respect to the tables obtained for surfaces in initial state is observed, and this could result in a slightly lighter surface.

Regarding the specularity level, the shape is far from being "diffuse". If we observe the CIE (S1) index, its values are lower than those for the roads HSI type (S1 $1.1 / 1.2)$. However, the index of the LAL-CIC system is still high $(\mathrm{AD} \approx 1.4 / 1.5)$ and this would indicate a specularity level, which is not very different from the studied roads in initial state.

\section{CONCLUSIONS}

The study reveals that it is possible to infer a "steady state" for surfaces of about three years of use. The initial stabilization period resulted longer than the obtained in the European research on traditional roads (between four and six months).

Besides, by obtaining measurements with coinciding results within periods of more than four years, it is also likely to consider a steady state that would remain for longer periods. Unlike the research of Bodmann et al, we cannot infer the shift from a more "specular" matrix to a more "diffuse" matrix. The obtained results indicate that the new and used surfaces stay practically with the same specularity, but changing the position and the peak reflection shape. Possibly this explains what was found in the previous study (FHWA, 2007), that is, the important change in Ul with use without a significant alteration of Uo.

Finally, and as outstanding data for designers and planners, the shapes found do not coincide with standards CIE R3 or R4, and this highlights the importance of using r-tables representing correctly the surfaces of our region in the designs.

\section{ACKNOWLEDGEMENTS}

The authors would like to thank CIC PBA, where P.I. is member of the Career of Scientific and Technological Researcher and A.A. and B.B. belong to the Professional Staff.

\section{REFERENCES}

CIE, 1982. Commission Internationale de l'Eclairage, Publication $\mathrm{N}^{\circ}$ 30-2 - TC 4.6, Calculation and measurement of luminance and illuminance in road lighting, France.

De Boer, J., Cohu, M., Schreuder, D. 1967. Public Lighting, Philips technical Library, The Netherlands.

Ixtaina, P; Vidal P, 2013. Road surface lightness and energy efficiency in road lighting, 12th European Lighting Conference "LUX EUROPA, Poland.

De Boer, Van Bommel, 1980. Road Lighting, Philips technical Library, The Netherlands.

Bodmann H, Schmidt H, 1989. Road surface reflection and Road Lighting: Field investigations, Lighting Research and Technology 21(4) 159-170.

Ziegler W. 1980. Reflexion trockener und feuchter Strassenbelage Dissertation, Universitat Karlsruhe, Germany. 
Federal Highway Administration, 1986. Reflective characteristics of roadway pavements during wet weather, Report No FHWA/RD-86/104, USA.

Ixtaina, Pablo R; Vidal, Pedro A., 2005. Changes with use and age of reflection properties of road surface new types, CIE Midterm Meeting and International Lighting Congress, León, Spain.

Vidal, P.; Ixtaina, P., 2002. Application of a New Pavement Reflectometer, 2nd Balkan Conference and Fair in Lighting Balkan-Light'02, Proceedings, Istanbul, Turkey.

Ixtaina P, Vidal P, 2008. Argentinean road surface characterization, International CIE Symposium on road surface photometric characteristics: Measurement Systems and Results, Torino, Italy.

Vidal, P.; Ixtaina, P. ,2003. New method for characterising the reflection properties of road surfaces, CIE 25th Session, San Diego. USA: 